\title{
Pandemia, gobernanza y derechos humanos
}

\section{The pandemic, governance and human rights} 0

EDWIN VILMER FIGUEROA GUTARRA

Corte Superior de Justicia de Lambayeque

(Lambayeque, Perú)

Contacto: efigueroag@pj.gob.pe

https://orcid.org/0000-0003-4009-3953

\section{RESUMEN}

La COVID-19 ha colocado a la humanidad entera en un laberinto, similar al del Minotauro, que demanda escrutar complejas salidas para superar la pandemia. Nuestra vida se ha transformado radicalmente dadas las enormes restricciones a los derechos fundamentales en todos los países del orbe. En esa disyuntiva, resulta necesario realizar un reexamen del concepto de gobernanza y sus diversas variantes en relación con las políticas públicas, así como reevaluar la dimensión axiológica de los derechos humanos como elementos centrales a tener en cuenta en la denodada lucha por recuperar parte de nuestra vieja normalidad. En ese camino, la lucha contra la pandemia nos deja algunas enseñanzas de valor que es necesario destacar.

Palabras clave: COVID-19; pandemia; gobernanza; derechos humanos. 


\section{ABSTRACT}

The COVID-19 has placed the whole of humanity in a labyrinth, similar to that of the Minotaur, which demands scrutinizing complex exits to overcome the pandemic. Our lives have been radically transformed by the enormous restrictions on fundamental rights in all countries of the world. In this dilemma, it is necessary to reexamine the concept of governance and its various variants concerning public policies, as well as to reassess the axiological dimension of human rights as central elements to be taken into account in the courageous struggle to recover part of our former normality. On this path, the fight against the pandemic has taught us some valuable lessons that should be highlighted.

Key words: COVID-19; pandemic; governance; human rights.

Recibido: 11/05/2021 Aceptado: 25/05/2021

La pandemia de COVID-19 está exacerbando las violaciones ya existentes de derechos humanos y propiciando otras. No obstante, también está estimulando oportunidades para promover la agenda de los derechos humanos.

OXFAM

\section{INTRODUCCIÓN}

Los años 2020 y 2021 nos legan una lección muy compleja y de difícil asimilación de aprendizaje: no obstante los avances sustantivos acumulados en los últimos quinquenios, en materia de derechos humanos y a nivel de sistemas nacionales y regionales de protección de estos derechos, nunca antes habíamos apreciado, esta vez con incredulidad, una deconstrucción tan manifiesta, un retroceso tan marcado, un camino en reversa tan discutible de nuestras libertades públicas, en buena cuenta, como consecuencia de la pandemia de la COVID-19. 
Se trata, pues, de un mal que aún amenaza, con fuerza constante, nuestros tradicionales modos de vida, y que habría hecho incluso desaparecer aquella «vieja normalidad» a la que estábamos acostumbrados. Inclusive esta crisis pone en entredicho, dadas sus múltiples manifestaciones, si acaso hemos de recuperar el modus vivendi de libertades fundamentales que acumulamos en decenios, de una tendencia que fue consistente en su matiz de progresividad de los derechos humanos, pues siempre opusimos la tesis del crecimiento inexorable de los derechos de la persona humana frente a posibles, y hasta muy lejanos, escenarios de regresividad de los derechos de esta naturaleza.

Hoy, enfrascada la humanidad en constantes dilemas de vacunas y medidas para la reducción de los contagios, las democracias del mundo están orientadas a decisiones urgentes en el plano de la salud, de tal forma que las demás esferas del quehacer humano parecerían relegadas a un segundo plano. Intuimos que la crisis es temporal, pero no tenemos certeza alguna de cuándo volveremos a un panorama cercano a nuestro modo de vida hasta entonces acostumbrado, sobre todo caracterizado por la convivencia en democracia de amplias libertades y siempre matizado por un avance cualitativo de las políticas públicas en materia de derechos humanos.

A pesar de diversos retrocesos, queremos recoger la idea, y así lo proponemos, de que los derechos humanos persiguen rescatar un aliento de inalienabilidad, y que en medio de la incertidumbre creada por la COVID-19, los tiempos venideros han de consolidar que, aun en panoramas inciertos de pandemia, es obligación moral de la sociedad civil un necesario apuntalamiento de los derechos de primer orden de la persona. Y ello se logra con medidas adecuadas respecto de una buena gobernanza, una de las esferas centrales hacia la cual apunta nuestro objeto de análisis.

Bajo el marco del razonamiento que antecede, el presente estudio desarrolla varias de las reflexiones expuestas supra y pretende 
destacar un análisis mixto de la relación que se debe construir entre las nociones de pandemia y gobernanza; de esa forma, las interrelaciones entre ambos conceptos definen incidencias que persiguen consolidar una tesis principal de defensa de los derechos humanos en contextos complejos, que ponen a prueba, por cierto, todos los avances hasta ahora logrados en la materia.

Con este fin, es importante enfatizar cómo la pandemia que hoy nos afecta ha trastocado, contra todo pronóstico inicial, las relaciones en sociedad y, en especial, cuáles afectaciones relevantes ha supuesto esta misma plaga en los conceptos de gobernanza, noción que debe distinguirse de la idea de gobernabilidad. Para ello es relevante destacar que distintas acepciones de gobernanza, que siempre entendimos como una propuesta de viabilidad, prácticamente han caído, por la misma pandemia, en contradicciones de definición, las cuales nos obligan a replantear ideas de uso afianzadas hasta hoy, para dar paso - lo entendemos así- a una idea de necesaria dosis de pragmatismo de las políticas públicas en el combate contra la COVID-19.

Y aludíamos a una noción de revisión del statu quo, como hasta entonces entendimos las políticas públicas más tradicionales, pues habremos de ver, sucintamente, por qué el accionar de las democracias tradicionales frente a la pandemia parece no haber surtido los efectos necesarios y, por el contrario, son precisamente varias economías desarrolladas las que acusan un desempeño hasta cierto punto negativo frente a la pandemia, expresado ello en altos niveles de muertes y un profuso crecimiento de contagios en la lucha contra la propagación de la enfermedad. Por el contrario, otras naciones de menor tamaño, aunque no exentas de problemas, han acusado una respuesta de mejor alcance, en términos de ahorro de vidas humanas, frente a una aparentemente sólida maquinaria pre-COVID-19. 
En esa lógica conceptual, los efectos de estas disparidades en materia de derechos humanos son destacables, en tanto en cuanto las políticas públicas de los gobiernos finalmente inciden en las perspectivas sistémicas de los derechos humanos, y es este último balance el que merece valorarse.

En esa medida, merece aprobación social una política pública que logra resultados tangibles si logra salvar más vidas humanas frente a los embates de la pandemia, así como merece desaprobación social aquella política de orden público que, bajo un espíritu negacionista de la enfermedad o anquilosada en una concepción tradicional de hacer las cosas como siempre se hicieron, finalmente exhibe resultados negativos en el acápite más relevante de la acción social de un país: el bienestar de vida de sus ciudadanos. Y en definitiva, si la tasa de mortalidad de un país por COVID-19 es alta, o sumamente compleja en otros factores de medición, existen estándares que señalan que hubo inacción o bien las acciones emprendidas fueron lamentable y manifiestamente insuficientes.

Concluimos con algunas reflexiones de valor, y en este segmento de ideas, una interrogante fluye con diáfana nitidez: a pesar de todas las incidencias negativas que ha acarreado este nuevo coronavirus en el campo de los derechos humanos, ¿es posible extraer enseñanzas positivas de esta pandemia? Se trata de una pregunta retadora que pone de manifiesto si ante tantos escenarios negativos que nos ha deparado la pandemia, acaso podemos adoptar algunas lecciones y enseñanzas a futuro. Arriesgamos una respuesta positiva a esta interrogante en la medida que en este contexto en el cual nuestros derechos se han reducido de modo ostensible, justificando eso una palmaria preocupación, la COVID-19 nos enseña a valorar, de mejor forma, aquellas otras libertades de que antes gozábamos en forma cuasi irrestricta. Así, quizá vivíamos, cual alegoría volteriana, en el mejor de los mundos posibles, a pesar de todos los defectos de las democracias constitucionales, y en realidad no lo sabíamos. 
Pues bien, es moralmente exigible, entonces, la necesidad de acotar que resulta un imperativo categórico la exigencia de demandar que se restauren nuestros viejos derechos, pero, al mismo tiempo, es razonable entender que no existe comprensión cabal del mundo, de sus valores, de sus alcances, de sus más íntimas manifestaciones de valor democrático, sin un correlato de observancia, respeto y tutela in crescendo de los derechos humanos.

En esa línea de reflexión, no aludimos a la concepción miltoniana de un paraíso perdido, ni a la visión de Moro de un mundo utópico, sino simplemente a la exigencia directriz de que las políticas públicas procuren una línea material de protección de los derechos de la persona, tal y como se han manifestado los sistemas regionales de protección de los derechos humanos una vez declarada la pandemia. Esto es, son aceptadas las medidas extraordinarias de los gobiernos en cuanto a estados de alarma, de excepción o de calamidad, en sus respectivas latitudes, pero siempre que ello se exprese respetándose las líneas tutelares de salvaguarda de los derechos del individuo, sin excesos manifiestos, sin expoliación incongruente de derechos y sin despojo irrazonable del contenido esencial, del núcleo duro, del fin último de los derechos humanos.

En ese propósito, los derechos humanos deben salir fortalecidos en su valor material, a pesar de los difíciles contextos a que han sido sometidos por causa de la COVID-19.

\section{PANDEMIA Y DERECHOS}

Analizar la pandemia de la COVID-19 desde la perspectiva de los derechos en su acepción general nos conduce inevitablemente a una noción de restricción de libertades. Fue así durante la peste negra de 1347 y los años siguientes en Europa, plaga que se llevó alrededor de 75 millones de vidas. En ese entonces, las personas aquejadas por el mal eran encerradas por la fuerza en sus propios domicilios 
y se marcaba las puertas de las casas para evidenciar que allí había un enfermo. Ocurrió también una sesgada restricción de los derechos de la persona durante la gran pandemia de Londres de 1665, la cual cobró no menos de 100000 vidas, cuando el sistema de cuarentena adquirió cierta organicidad, y nadie podía entrar ni salir de una casa donde había muerto alguien de peste por espacio de 40 días.

De la misma forma, los derechos en materia de salud se redujeron a su mínima expresión durante el período de la gripe española de 1918, dado que la respuesta hospitalaria de los Estados fue deficitaria en extremo, elemento que incrementó el número de pérdida de vidas humanas hasta un estimado de 50 millones, es decir, hubo más muertes a causa de este mal que durante la Primera Guerra Mundial, acaecida entre 1914 y 1918. La pandemia de aquel entonces mató más personas que la gran conflagración mundial.

Es importante anotar que un rasgo particular de la COVID-19 es su ocurrencia durante una etapa en la cual la tecnología ha logrado avances cualitativos extraordinarios. Incluso el genoma del nuevo coronavirus fue descifrado en enero de 2020, y aun cuando se trata de una enfermedad cuyas incidencias y efectos todavía exigen estudios más exhaustivos, podemos aseverar categóricamente que hoy, a diferencia de las épocas de las grandes plagas referidas, la ciencia, indudablemente, se encuentra de nuestro lado, en cuanto a avances técnicos para luchar contra muchos males. Sin embargo, todas esas sumas, frente a la actual pandemia, acusan preocupante insuficiencia, sobre todo por la dimensión todavía desconocida de esta pandemia y por su condición de «riesgo global».

En relación con lo afirmado, señala Sanahuja (2020) que la COVID-19 genera dos crisis que convergen: una ecológica y otra médico sanitaria, y en ello 
inciden tres factores causales: a) la actividad humana, que causa la desintegración de ecosistemas a un ritmo cataclísmico; b) la existencia de una «virusfera» gigantesca, con un gran número de organismos patógenos parasitarios; y c) la creciente tendencia de esos organismos parásitos a buscar nuevos anfitriones donde alojarse, siendo los candidatos obvios los seres humanos, dado su número y omnipresencia (p. 32).

Acota el mismo autor:

como expresión de un «riesgo global», el alcance sistémico de la crisis creada por la enfermedad de la COVID-19 parece responder más a la falta de preparación de los gobiernos, las sociedades y la respuesta multilateral, que al patógeno mismo, aun admitiendo las características de este virus, muy dañino cuando se manifiesta, pero también difícil de diagnosticar, ya que puede permanecer hasta doce días sin manifestarse, y que en muchos portadores se muestra asintomático (2020, p. 31).

Lo antedicho tiene un efecto relevante en el campo de los derechos, pues las pandemias ponen a prueba hasta dónde los seres humanos han consagrado sus libertades públicas. Al respecto, es de destacar una dimensión positiva en ese contexto de derechos logrados, dado que podemos alegar que un haz de instrumentos normativos, así como un importante estándar de decisiones jurisprudenciales en materia de derechos humanos, en buena cuenta, confieren a los individuos una importante noción expectaticia respecto de sus derechos, configurándose así una dimensión positiva de estos. Nos referimos aquí a un cúmulo de potenciales elementos para el ejercicio del derecho de petición, el cual le asiste a toda persona por su sola condición de ser humano.

Muy distinto era el horizonte de esta posibilidad de ejercicio de derechos durante las otras grandes plagas en los siglos pasados, ya que las personas querrían haber optado por demandar de sus 
Estados o sociedades un ejercicio de protección de sus derechos, mas ese conjunto normativo de elementos no existía, y bajo una lógica utilitarista, el individuo se limitaba a defenderse con lo único que poseía: su intuición, sus creencias y sus emociones, sin esperar mayor acción de los Estados.

La pandemia actual, por otro lado, muy a nuestro pesar, destaca una dimensión negativa de los derechos, pues logra demostrar, las más de las veces, que el ejercicio de los derechos, principalmente los de la salud y la vida, admite flagrantes limitaciones y restricciones, más aún frente a un fenómeno todavía poco conocido como la COVID-19, cuyo comportamiento es todavía impredecible en muchos aspectos, y ello causa crisis de gobernanza en los Estados, por acción u omisión.

Entonces, ello se traduce en que los avances logrados en la consolidación de los derechos humanos son sometidos a duras pruebas de corroboración. En ese tránsito nos damos cuenta de que lo que dábamos por cierto y descontado, por ejemplo, la atención inicial suficiente de un servicio hospitalario de salud, frente a problemas de saturación de oxígeno por causa de la COVID-19, choca, en la dura realidad, con la ausencia de equipos para estas atenciones especiales, o la insuficiencia de camas de unidades de cuidados intensivos, o bien la falta de personal sanitario entrenado para estos avatares.

Lo descrito es quizá, y es tan solo un ejemplo, una de las facetas más complejas de los escenarios que nos plantea la COVID-19. Nos referimos a que hemos dado por cierto, pues nos asiste ese derecho expectaticio, que el Estado cumple la implementación de un sistema de salud adecuado. Esto último constituiría la dimensión positiva de los derechos humanos en la concepción que presentamos y, sin embargo, con ese mismo rigor, la faceta negativa se expresaría en la difícil realidad diaria que plantea la enfermedad para derechos humanos de envergadura como el de la salud. Ello nos lanza a un 
balance de dura asimilación del contexto verdadero de nuestros derechos, con pronóstico por ahora desfavorable.

Podríamos ejemplificar nuestra posición con otro fenómeno quizá distinto a la COVID-19. Esto pudo ocurrir con desapariciones forzadas de personas, asesinatos masivos de poblaciones $u$ otras tantas situaciones de las que, a diario, son testigos los sistemas regionales de protección de los derechos humanos. Y sin perjuicio de lo señalado, hay una diferencia sistémica con la actual pandemia. Ello se expresa en la naturaleza pluriofensiva de este mal, en tanto otras lesiones a los derechos humanos focalizan el daño y el universo es más cerrado. La COVID-19 es una enfermedad que se caracteriza por atacar a todos los seres humanos sin distinción de rangos, estatus social o condiciones personales. En esa lógica, todos nos podemos contagiar, nadie queda a salvo de los efectos que pudiera causar la enfermedad, y ello obliga a multiplicar los esfuerzos de los gobiernos, los cuales, a la fecha, acusan un preocupante nivel de insuficiencia, pues los Estados y la sociedad parecemos caminar a pie en los avances de progreso frente al mal, en tanto que la COVID-19 nos demuestra que viaja, figurativamente, en medios motorizados.

¿Cuál habría de ser entonces el panorama de los derechos humanos en su perspectiva general frente a la COVID-19? Podemos tentar un ejercicio aproximado, no definitivo de escenarios, y podemos realizar un ejercicio cronológico de acercamiento: en el 2020 la pandemia se consolidó como la principal amenaza pública en materia de salud y los Estados esbozaron respuestas que notoriamente fueron incompletas, a pesar de los esfuerzos desplegados. Es más, no vimos en el 2020 un retroceso del mal y, por el contrario, hacia fines del año, el panorama era el de posible mayor propagación del problema, tema proyectado con las variantes, de mayor efecto de contagio, del Reino Unido, Sudáfrica y Brasil. 
El 2021 habría de ser el período de vacunación en muchos países, mas es necesario anotar que las vacunas por sí mismas no representan el fin de la enfermedad. Al respecto, vale señalar una distinción que realizan los científicos. En rigor, se trata de que la vacuna propiamente no impide el contagio per se, sino que logra, y ello es plausible, que quien resulte contagiado no desarrolle los efectos más severos del mal, e inclusive la vacuna evita la muerte misma.

Por lo tanto, el riesgo de contagio ha de seguir existiendo y, al respecto, lo positivo será que el número de muertes irá disminuyendo. ¿Cuál es el panorama de los derechos en este contexto? Creemos que seguirán las restricciones y lo apreciamos ya en las medidas que adoptan los gobiernos: toques de queda ampliados, restricciones adicionales de atención de los negocios, nuevas limitaciones de movilidad de las personas, etc.

El contexto de mejora de libertades públicas mejoraría en el 2022, mas ello habrá de definirse en función de los efectos logrados por las vacunas y, sobre todo, a partir del análisis costo-beneficio de las medidas adoptadas por los Estados. Sin embargo, sí es tangible que la situación de los derechos ya no empeorase, pues entendemos que la crisis ya habría tocado fondo entre los años 2021 y 2022. El aspecto contingente o hipotéticamente contrario a destacar, de imprescindible mención por necesidad de transparencia con nuestro razonamiento, es que las mutaciones del virus causen crisis adicionales y pongan en jaque nuevamente los sistemas de salud. No obstante, debemos confiar en que esa situación no se produzca.

Anotado lo expuesto, el 2023 habría de ser el año con una mejor recuperación de la humanidad y de nuestros derechos en relación con los efectos de la COVID-19. Los Estados irán reduciendo, gradualmente, las limitaciones impuestas por causa de la pandemia en los años anteriores y podremos percibir un clima de progresiva 
recuperación de nuestros derechos. Naturalmente todo esto se supedita a que los indicadores de retroceso de la enfermedad sean consistentes, y ello habrá de permitir, sobre una base más sólida, que los Estados puedan adoptar decisiones basadas en un contexto verificable de la eliminación paulatina de la pandemia.

Bajo el análisis desarrollado, podríamos llamar al 2024 y los años siguientes como los de la pospandemia, que se caracterizarían por volver, en gran medida, a nuestra normalidad de antaño, aunque es ciertamente presumible que algunas medidas de control habrán de seguir vigentes, pues la previsión es que la COVID-19 se convierta en un problema estacional y deje de ser la pandemia con las características que hoy posee. Desde ese eje, esperamos una mejor recuperación del goce y ejercicio de los derechos de las personas.

Los derechos apuntan, en consecuencia, a recuperar su ejercicio, ya que esa es la naturaleza implícita de su desarrollo y, sin embargo, no podemos negar el carácter de temporary pause, es decir, de pausa temporal en que nos pone la pandemia.

\section{LA GOBERNANZA COMO CONCEPTO MATERIAL}

Un concepto central en este estudio es la incidencia de la noción de gobernanza, acepción a la cual pretendemos conferirle un rol relevante desde una dimensión material, esto es, de identificación de sus rasgos más distintivos desde una visión de esencia de la idea expuesta.

Antonio Guterres, secretario general de las Naciones Unidas, reseña que «necesitamos con urgencia pensar de manera innovadora sobre la gobernanza global y el multilateralismo, y adaptarlos al siglo XXI» (Noticias ONU, 2020, "A la altura de los tiempos», párr. 2), y acota sobre esto mismo que «el mundo precisa de un multilateralismo en red, con vínculos y cooperación sólida entre organizaciones internacionales y regionales, instituciones financieras 
internacionales y otras alianzas e instituciones globales» (Noticias ONU, 2020, «A la altura de los tiempos», párr. 3). Complementa estas reflexiones agregando que «Naciones Unidas deberían mejorar la eficacia de su contribución a la gobernanza global. [...] la responsabilidad principal de garantizar el funcionamiento de esa gobernanza recae en los Estados miembros» (Noticias ONU, 2020, «A la altura de los tiempos», párr. 9), así como «La reforma de la gobernanza global no sustituye a la acción colectiva de los Estados miembros para superar los desafíos comunes» (Noticias ONU, 2020, «A la altura de los tiempos», párr. 10).

Desde otra perspectiva, González Placencia (2013) señala que:

una sociedad bien ordenada, que ha resuelto el tema de la gobernabilidad en sentido democrático, es aquella en la que, como señalaba John Rawls (1996), los intereses de todos los individuos racionales pueden acompasarse en una voluntad política que les permite reconocerse como colectivo, al tiempo que ellos mantienen los rasgos - su religión, su raza, su doctrina política - que los hacen particulares (p. 8).

El panorama de los derechos, a tenor de lo afirmado, es muy complejo. Bachelet (2020) acota:

Estamos ante una situación de gobernanza internacional muy difícil. Uno habría pensado que esta pandemia hubiera permitido poder decir «tenemos que trabajar todos juntos», sin embargo, es algo que no se ha dado todavía, no se ha dado ni entre los más grandes, ni se ha dado entre los más pequeños, o los medianos (p. 29).

Reseñados los conceptos que anteceden, los cuales inciden en definir una idea muy inicial de gobernanza y, sobre todo, contrastarla con el contexto actual que vivimos, es relevante diferenciar, inicialmente, gobernanza de gobernabilidad. La gobernabilidad 
mantiene una perspectiva gubernamental dominante o exclusiva, y parte del supuesto de [...] un gobierno dotado con las capacidades necesarias [...] para dirigir a la sociedad, mientras que la perspectiva de la gobernanza supone que por sí solos los gobiernos, aunque sean legítimos [...] no pueden hacer frente a varias cuestiones públicas complejas, cuya solución exige la labor conjunta del gobierno y sus ciudadanos (Zavala de Alba, 2015, p. 16).

Efectuada esa necesaria diferenciación, queremos ser puntuales en destacar que la COVID-19 se ha encargado, en este período de acciones gubernamentales frente a la pandemia en 2020 y lo que va de 2021, de desbaratar aquello que entendíamos por supuestos dados. De esa forma, ha afectado radicalmente a nuestras definiciones tentativas de democracias mejor preparadas para enfrentar adversidades de distinto rango. La pandemia parece lograr que se reescriba, por ahora, la historia misma de la humanidad.

Lo expuesto nos sirve de marco para reflexionar sobre los aspectos pragmáticos de la gobernanza. Recurrimos así a una valiosa reflexión de la profesora Ngaire Woods (2021, p. 22), quien anota un escenario contradictorio respecto de la COVID-19 entre dos naciones desarrolladas -EE. UU. y Reino Unido-y otras dos naciones con menores avances - Senegal y Sri Lanka - para destacar resultados notoriamente adversos en su lucha contra la pandemia: bastante desfavorables para los dos países de habla inglesa y, cuando menos, de expectativa alentadora para las dos modestas naciones.

La profesora Woods toma como referencia, para su importante contrastación, una comparación prepandemia de estos países en el Índice Global de Seguridad Sanitaria (GHSI), herramienta global que califica la capacidad de los países para prevenir, detectar y reportar una infección, y responder rápidamente frente a brotes de enfermedades. La misma autora anota que, declarada la COVD-19 y valorada la actuación de los países referidos, «estos rankings parecen absurdos», y anota un aspecto de suma importancia: «los 
10 países más afectados por el COVID 19 en términos de muertes por millón de habitantes están entre los primeros 20» (Woods, 2021, p. 22) del mencionado ranking.

En el desarrollo de su tesis, Woods destaca los países cuyas políticas de gobernanza merecen un análisis. Señala así, como referimos antes, el caso de Senegal, y menciona que su ubicación en el GHSI era el puesto 95, con una calificación de 37,9-Estados Unidos, en el primer puesto, registraba 83,5-, y destaca las acciones inmediatas de dicho país contra la pandemia desde el mismo enero de 2020.

Refiere Woods (2021) que el país africano

desplegó unidades de testeo móviles, estableció un sistema de rastreo de contactos y construyó instalaciones de aislamiento en hospitales y hoteles. El gobierno también prohibió de inmediato reuniones públicas, impuso un toque de queda nocturno, restringió el turismo doméstico y suspendió los vuelos internacionales. En octubre, el país había registrado alrededor de 15,000 casos y 300 muertes (p. 22).

Añade a su comparación el caso de Sri Lanka, país ubicado en el puesto 120 del GHSI. En este caso:

el gobierno desplegó al ejército para ayudar y puso en marcha testeos rápidos desarrollados localmente. Estableció un régimen riguroso de rastreo de contactos, brindó ayuda a quienes estaban aislados y detectó obligatorio el uso de mascarillas faciales en público. En noviembre de 2020, el país había reportado solo 13 muertes por COVID 19 (Woods, 2021, p. 22).

Además, acota una pregunta que invita a la reflexión: «Si estos países pobres pudieron manejarse tan bien, ¿por qué EE. UU. y Reino Unido fracasaron?» (Woods, 2021, p. 22). Ciertamente es un ejercicio harto complejo responder esta interrogante, pues se ponen en juego muchos factores. Sin embargo, debemos esbozar algunos 
trazos tentativos a modo de nueva pregunta: ¿manejaron Senegal y Sri Lanka mejores estándares de gobernanza en relación con sus homólogos EE. UU. y Reino Unido?

Creemos, intentando ordenar una respuesta congruente a lo arriba planteado, que primó, sustantivamente, una respuesta pragmática de entorno inmediato frente a la situación producida por la COVID-19, de un lado; $y$, de otra parte, coincidiendo con la profesora Woods, podemos afirmar que la gobernanza siempre puede dejarnos lecciones brutales, al tiempo que, en esencia, la gobernanza per se no implica un concepto engominado y sujeto a delimitaciones teóricas en exceso formalistas.

Hemos de insistir en que la diferencia de las realidades de los países referidos es implícitamente manifiesta. Sin embargo, no hemos de llegar a la falacia de generalización de que todo, al fin y al cabo, es distinto, y que nada puede ser igual. En efecto, es distinto manejar un país de más de 300 millones de habitantes, como EE. UU., a hacerlo con un país de alrededor de 16 millones, como Senegal, pero vayamos, en concreto, a que son exigibles, de suyo, en contextos de pandemia, acciones inmediatas de los propios Estados, así como decisiones de gobierno que apunten a respuestas inmediatas en resultados. En tanto, se puede acotar tres escenarios: en un primer rango, nos encontramos ante un nuevo tipo de crisis, como en el caso de la COVID-19, y esto causa un segundo contexto de amenaza a la salud humana; ello deja abierto, lo hemos constatado en todo este tiempo, un tercer campo: son exigibles resultados que amainen los efectos de la pandemia, y sin ellos, siempre habrá más muertes y más adversidad.

De la misma forma, conviene analizar brevemente, desde la lógica de la gobernanza misma como abstracción, por qué un país con una buena ubicación en el barómetro GHSI acusa una respuesta bastante deficitaria frente a la pandemia, en tanto que un 
país relegado en esa misma lista ha obtenido mejores estándares de rendimiento en concreto frente al avance de la COVID-19.

Creemos, en fórmula de hipótesis, que la pandemia ha modificado todos los parámetros de actuación de los gobiernos en materia de perspectivas de desarrollo de la misma COVID-19, y lo ha hecho también en cuanto a estándares usuales en materia de salud; finalmente, sin que esta sea una lista exhaustiva, sí influye la pandemia sans doute, esto es, sin duda, en la tradicional concepción de gobernanza, modificándola, de raíz, frente a los complejos escenarios que denota la pandemia. Desarrollemos uno a uno estos tres aspectos señalados: perspectivas, salud y gobernanza.

En relación con el ítem de perspectivas, la evolución inicial de la COVID-19, es de anotarse, condujo a la proyección del término de una primera ola de la enfermedad, y naturalmente ello trajo consigo cierta visión de que lo peor ya había pasado, hacia el tercer trimestre de 2020, para muchos países. Sin embargo, la segunda e incluso la tercera ola de esta pandemia parecen ser realidades complejas que, de hecho, acarrean ya más fallecimientos que la primera.

¿Faltó aquí proyección de los gobiernos? Creemos que las olas posteriores eran fenómenos previsibles, pero, en rigor, ante la complejidad de una enfermedad cuyos estándares de desempeño son desconocidos, la realidad misma de la evolución del mal desbordó los escenarios de actuación de los gobiernos y puso a la humanidad misma en una situación que hoy es permanentemente deficitaria en términos de salvación de vidas. Eso lo demuestran, día a día, las estadísticas de la Organización Mundial de la Salud.

En el ámbito de la salud, la COVID-19 ha demostrado, de igual forma, que toda previsión de infraestructura hospitalaria, incluso de los países mejor ubicados en el GHSI, ha demostrado ser marcadamente insuficiente. La evolución de la misma COVID-19 y de sus variantes, que hacen inclusive más contagiosa la enfermedad, 
viene generando una presión hospitalaria más fuerte sobre los sistemas de salud, pues a más contagios, más exigencias de camas en los hospitales y, con certidumbre, la velocidad de implementación de servicios de salud en cuanto a camas para los casos más graves no necesariamente habría de ir al mismo ritmo que una mayor demanda de camas de Unidades de Cuidados Intensivos en el sistema de salud. Por consiguiente, de nuevo la cruda realidad desborda la previsión de las autoridades en salud.

El balance de los aspectos acotados nos conduce, con lógica de inferencia y como tercer aspecto que se tiene que delimitar, a una crisis de gobernanza que nos replantea la exigencia de revisar los conceptos tradicionales hasta ahora construidos nominalmente, es necesario replantear, incluso, su revisión. En esa dinámica conceptual, un primer trazo de conclusión nos lleva a inferir que la buena ubicación de un país en el estándar GHSI no asegura una mejor respuesta frente a una pandemia, y los ejemplos esbozados por la profesora Woods son más que ilustrativos y nos relevan de un comentario más exhaustivo.

Sin perjuicio de lo afirmado, sí es importante anotar, incluso como la primera importante conclusión de este estudio, la necesidad de revisar los conceptos de gobernanza construidos en relación con el parámetro GHSI y la misma realidad de la COVID-19. Ha sido concluyente que se han venido abajo supuestos que asociábamos con naturalidad. Esto es, en concreto, que una economía desarrollada con toda lógica conducía a estándares de respuestas adecuadas frente a una pandemia. ¿Por qué? Porque el barómetro GHSI así parecía garantizarlo.

Podemos esbozar una conclusión importante, a partir de un estudio de Naciones Unidas (2008), y ello reside en que

las reformas de la gobernanza promueven los derechos humanos cuando mejoran la capacidad del Estado para cumplir su 
responsabilidad de ofrecer bienes públicos indispensables para la protección de cierto número de derechos humanos, como el derecho a la educación, a la salud y a la alimentación (p. 2).

En ese orden de ideas, la mejor gobernanza se construye a partir de un enfoque de incidencia en los derechos humanos. Esto es, se trata de un binomio intrínseco en el cual la gobernanza requiere de los derechos humanos y estos de aquella.

\section{4. ¿NUEVA DIMENSIÓN DE LOS DERECHOS HUMANOS A PARTIR DE LA PANDEMIA?}

Oxfam destaca una reflexión de interés respecto de la relación entre pandemia y derechos humanos, e identifica principios de relevancia. Anota, de esa forma, que «los cinco principios clave de los derechos humanos especialmente relevantes para las respuestas ante la pandemia son: igualdad y no discriminación, participación, proporcionalidad, dignidad humana y cuidados, y los derechos a la libertad de expresión, de reunión y a la información» (Oxfam, 2020, p. 4). Se trata, creemos, de ejes esenciales para la construcción de una política pública idónea en derechos humanos.

Igualmente, Nash Rojas (2020) aporta que «la crisis generada por la pandemia del COVID-19 no es solo una crisis sanitaria, sino que también es una crisis de Derechos Humanos que obliga a los Estados a adoptar una respuesta multidimensional que los incluya dentro de su diseño» (p. 45). A esa reflexión agrega:

en este contexto un riesgo evidente ha sido que se abran espacios para pensar la crisis del COVID-19 como una oportunidad propicia para establecer una suerte de «receso» en las obligaciones de los Estados en materia de Derechos Humanos o como una oportunidad para avanzar en agendas restrictivas en materia de Derechos Humanos (p. 46). 
¿Y dónde se produce la mayor incidencia de esta compleja interacción entre pandemia y derechos humanos? En el campo del derecho a la salud. De este modo, señala Nash Rojas (2020):

sin duda, el primer gran desafío y la mayor urgencia generada por la pandemia era enfrentar la crisis de salud pública. El Estado chileno tenía el deber de enfrentar la pandemia garantizando a todas las personas sujetas a su jurisdicción el acceso a salud bajo los principios de accesibilidad, calidad, adecuación y aceptabilidad (p. 49).

En efecto, la salud resulta un bien frontalmente agredido por la COVID-19, y de esa forma:

la pandemia es un riesgo para todos nosotros, pero tiene efectos desproporcionados en la salud y en los medios de vida de ciertos grupos y de ciertas comunidades. El virus no discrimina, pero los impactos sílo hacen: los más pobres, los más vulnerables, ya estaban en riesgo previo (Bachelet, 2020, p. 17).

Esas exigencias sobre la salud llevan, de igual forma, a prestar más atención a las políticas públicas, y Bachelet (2020) aporta una reflexión especial: «Estoy convencida de que las políticas públicas tienen que adaptarse a las personas y no las personas a las políticas públicas, porque es la única manera de dar respuestas efectivas» (p. 24).

En balance de las líneas de reflexión desarrolladas supra, no podemos dejar de anotar que un efecto directo de la pandemia de la COVID-19 es su incidencia en el campo de los derechos de la persona, desde una acepción general, y he aquí que nos planteamos si acaso esta crisis sanitaria trae consigo cambios en nuestra visión de los derechos humanos, tal como la conocemos hasta hoy.

Los derechos humanos, a partir de la compleja coyuntura trazada por la COVID-19, debemos aceptarlo así, nunca retrocedieron 
tanto como en estos tiempos desde que, en Wuhan, China, hacia inicios de 2020, se detectara el primer caso de esta enfermedad. El resultado, a poco más de un año de la pandemia, es un cuantioso número de fallecidos, más de 3 millones hacia abril de 2021.

Anotamos el número de muertes porque es el indicador estadístico que mejor describe el contraste final a que son sometidos los derechos humanos. En efecto, no podemos dejar de referir que se ha restringido severamente, al decretarse medidas de confinamiento a nivel mundial, nuestro derecho de locomoción, lo cual afectó, con creces, nuestra libertad de tránsito. De igual manera, alternativas de esparcimiento como cafés, cines, teatros y actividades conexas fueron cerradas por tiempo no determinado, lo cual implicó afectaciones al derecho al uso del tiempo libre, como componente de ese otro derecho mayor que es el derecho al libre desarrollo de la personalidad. Inclusive fue restringida la libertad de viajar, con lo cual la industria del humo blanco, esto es, el turismo, en sus diversas formas, acusó pérdidas considerables en los rubros de hotelería y vuelos aéreos. Así, toda la economía en conjunto ha resultado afectada y el receso mundial es una realidad ahora innegable.

$\mathrm{Y}$, sin embargo, si bien partimos de una tendencia a afianzar en el sentido de que todos los derechos humanos son de una misma naturaleza, esto es, que deberían ocupar todos los derechos, desde los civiles y políticos hasta los económicos, sociales, culturales y ambientales, una sola y misma categoría, no podemos negar la importancia mayúscula que revisten, lo reiteramos una vez más, los derechos humanos a la vida y a la salud, bienes jurídicos que ha atacado con mayor vehemencia la COVID-19, y cuyas cifras acumuladas a 2021, en términos de daños, contextualizan los alcances de una pandemia que ha puesto contra las cuerdas a la humanidad, y que la obliga a adoptar medidas que a su vez son constantemente replanteadas, dada la naturaleza cambiante de la enfermedad misma. 
Debemos poner énfasis, por otro lado, respecto a estos dos bienes jurídicos enunciados, a algo importante: si bien la salud humana se ha visto afectada en forma mayúscula por el desborde de la infraestructura de salud pública en hospitales de todo el mundo, puntualicemos que, al fin y al cabo, la salud es un bien en esencia recuperable. Esto es, aun en las condiciones menos favorables, un paciente hospitalizado que obtiene su alta médica ve en el horizonte inmediato o mediato la perspectiva de una recuperación psicoemocional y física, quizá paulatina, pero que al menos le asegura un probable retorno a sus condiciones de salud previas a la enfermedad.

No sucede lo mismo con el bien jurídico vida, cuya naturaleza, en casos extremos, huelga decirlo, pero vale anotarlo, es irrecuperable. En efecto, la pérdida de vidas humanas es un saldo verdaderamente doloroso por sus implicancias dado que, a simple vista, el número de muertes puede representar una fría cifra cuya causa es el grado de evolución que la enfermedad alcanzó en las personas. Sin embargo, es importante advertir que, detrás de cada cifra, en modo unitario, se esconden una historia de vida y seres queridos, un conjunto de perspectivas de realización truncadas, y una manifiesta contradicción: que el propio Estado no estuvo en la capacidad, por múltiples razones, de ofrecer una respuesta suficiente a un grave requerimiento de salud de un ciudadano, no obstante ser obligación de ese mismo Estado, bajo la noción de un deber especial de protección, garantizar la vida humana.

De esa forma, el Estado incumplió, por acción u omisión, con proteger el bien jurídico vida, elemento inalienable contemplado en el tercer artículo de la Declaración Universal de Derechos Humanos, instrumento que, podrá argüirse, es una herramienta de soft law, pero que, en buena cuenta, implica, también, moralische Verpflichtungen, es decir, obligaciones morales de los Estados a efectos de garantizar el pleno disfrute de los derechos más elementales de la persona. 
Es importante contextualizar entonces que, a pesar de los retrocesos anotados por los indicadores en todos los Estados respecto de las afectaciones observadas, y que estos tiempos transcurridos entre el 2020 y el 2021 parecen haber sido los de una epidemia sine die, esto es, sin término, es esperanzador afirmar, con vehemencia, que los derechos humanos conservan su calidad axiológica intacta. Es decir, podemos concluir que no han perdido su esencia. En ese sentido se han pronunciado tanto la Corte Interamericana de Derechos Humanos (2020a), así como la Comisión Interamericana de Derechos Humanos (2020), entidades que, en abril de 2020, a pocas semanas de instaurada la pandemia, manifestaron su preocupación, en sendos instrumentos, respecto de la situación de los derechos humanos en contextos de pandemia.

En síntesis, estas entidades avalaron, con cierta reserva, las acciones de los Gobiernos tendientes a las declaratorias de estados de excepción. Entre estados de alarma, emergencia o calamidad, y otras acepciones nacionales, instaron a los Estados a que esas medidas a adoptar, ciertamente duras, fueran determinadas dentro de los lineamientos de tutela de derechos adoptados por las entidades defensoras de los derechos protegidos por la Convención Americana de Derechos Humanos, así como dentro de los estándares de salvaguarda igualmente anotados por estas instituciones tutelares en el marco de sus Opiniones Consultivas, decisiones jurisprudenciales y otros instrumentos de protección de los derechos humanos.

Observemos aquí, con necesario interés, la importancia de dejar de lado esa connotación de meras declaraciones de intención con las cuales se tiende, a veces, a identificar los derechos humanos, alegándose que se trata de proposiciones semánticas sin concurrencia de ejecutoriedad, de coerción u obligatoriedad, con lo cual, de suceder así, las instituciones protectoras de los primeros 
derechos de la persona no ostentarían la calidad de organismos de tutela forzosa de los derechos humanos.

Lo arriba anotado descuida, en su visión de solo apreciar el árbol y no el bosque en su conjunto, que las cuestiones relativas a graves afectaciones de los derechos humanos son esencialmente judicializables, y que si bien determinado asunto puede requerir un necesario tránsito por el exigible agotamiento de la vía nacional, así como un estándar previo a nivel de la Comisión Interamericana de Derechos Humanos, en perspectiva aquello que sea decisión de la Corte Interamericana reviste todas las características de exigibilidad, en tanto constituya cosa juzgada. Valga la acotación de que es relevante graficar esa exigibilidad coercitiva de los derechos humanos a través de los fallos de la Corte, seguramente no numerosos pero sí vinculantes.

En efecto, si hacemos un balance de casos desde la primera sentencia de la Corte en el caso Velásquez Rodríguez vs. Honduras, en el año 1988 hasta la actualidad, un balance de la memoria de la Corte al 2019 nos arroja un total de 290 sentencias en casos contenciosos (Corte Interamericana de Derechos Humanos, 2020b, p. 60), lo cual no representaría una cantidad considerable de fallos. Por su parte, el Tribunal Europeo de Derechos Humanos es un órgano jurisdiccional que, sin Comisión Europea de Derechos Humanos desde 1998, en mérito a la entrada en vigencia del Protocolo 11 de la Convención Europea de Derechos Humanos, ha sentenciado solo en 2018 y 2019 un total de 1014 y 884 asuntos, respectivamente (European Court of Human Rights, 2020, p. 129).

Sin embargo, aludir al camino largo del tránsito de un caso interamericano no nos exime de un necesario comentario, en clave de construcción, que podríamos denominar la conceptualización de una nueva cultura jurídica de los derechos humanos, es decir, de una fuerza vinculante de los derechos humanos, desde las Opiniones Consultivas de la Corte hasta las Declaraciones tanto de la Corte 
IDH así como de la CIDH, lo que se refuerza, incluso, a través de la misma labor pedagógica de estos órganos cuando se trata de encuentros académicos, audiencias temáticas u otros mecanismos colaterales.

Tales elementos coadyuvan, es necesario ponerlo de relieve, y nos permiten entender, como alguna vez proponía en sus clases magistrales en la Washington College of Law el excomisionado Víctor Abrámovich, la importancia de atarse, cual Ulises, al mástil de los derechos humanos, reflexión que a su vez venía acompañada de otra idea sustantiva: es preferible lograr que la importancia de los derechos humanos se instale en el quehacer reflexivo de los jueces en materia de derechos fundamentales. Esto es, que el sistema interamericano vaya hacia los jueces, antes que los jueces dejen que las personas vayan al sistema interamericano de derechos humanos.

La frase que antecede es muy gráfica y habría de lograr el efecto de que si un juez conoce la dimensión, importancia y valía de los derechos humanos, entonces los casos sometidos a su conocimiento habrán de terminar, muy probablemente si las condiciones lo ameritan, con una conclusión de salvaguarda de los derechos humanos involucrados en el caso materia de examen. Ello requeriría un juez imbuido en los estándares más importantes en materia de derechos humanos. Por el contrario, un juez alejado del sentir, palpitar y vibrar de los derechos humanos, hará un tanto las veces de ese ejercicio de laisser faire, laisser passer, que alguna vez caracterizó al Estado watchman del siglo XIX. Esto es, habrá una conducta de anomia frente a los derechos humanos.

En resumen, consecuentemente, los derechos humanos ostentan una calidad de exigibilidad vinculante, y de ahí la importancia de percibir que, a pesar del duro escenario en materias justiciables que representa la pandemia, es importante inferir que los derechos de la persona no han perdido su carácter de progresividad, su 
realización gradual y su implícito espíritu de concreción que hoy caracterizan a las controversias en materia de derechos humanos.

\section{LECCIONES POSITIVAS FRENTE A ESCENARIOS NEGATIVOS}

Nos debemos interrogar, con manifiesta inquietud y porque la naturaleza de lo hasta ahora abordado así lo exige, si podemos sacar conclusiones positivas para el horizonte de los derechos humanos en los sistema regionales de protección, a pesar de los graves contextos descritos: imparable número de fallecidos por la COVID-19, desbordamiento de los sistemas de salud nacionales, paralización de las actividades económicas, restricción generalizada de los derechos de las personas, frustración generalizada de las expectativas de desarrollo de los ciudadanos, entre otros aspectos que hoy son moneda común en estas épocas de pandemia.

Pues bien, se hace necesario responder, una vez más, en clave de progresividad, y debemos afirmar, meridianamente, que la COVID-19, junto a todos los escenarios negativos descritos, también nos deja un considerable número de lecciones positivas, aun cuando pueda parecer poco congruente referirnos a aprender en medio de la misma tragedia humana a que la pandemia nos ha empujado. Anotemos algunas primeras, de orden general, y otras más específicas, en cuanto conciernen al tema de gobernanza.

Una lección válida para todos los ámbitos, lo entendemos de esa forma, es que la COVID-19 nos ha enseñado a valorar, con espíritu más reflexivo, el tiempo en nuestras vidas: tiempo de familia, tiempo de trabajo, tiempo libre, entre otras manifestaciones vinculadas a los derechos humanos, incluso respecto a la misma gobernanza.

Diríamos que el tiempo en familia hoy asume una nueva dimensión de valor porque el confinamiento obligó a una convivencia más en común y de mayor compartir entre las familias. De pronto la COVID-19 nos permitió distinguir, sin darnos cuenta, 
una dimensión de valía del tiempo familiar que antes transcurría ante el inexorable y veloz tránsito de una vida dominada por la modernidad y celeridad de las obligaciones laborales.

De otro lado, el tiempo de trabajo, igualmente, adquirió otra connotación. La obligada nota de presencialidad de las tareas en el trabajo, por efectos de la COVID-19, ha transitado hogaño hacia un escenario de virtualidad que, es cierto, exige mayor apego y entrenamiento en tecnología, pero, al mismo tiempo, se ve compensada por una representación digital que, en parte, ha reemplazado la exigibilidad de desarrollar tareas en forma física. Y por supuesto que esto redunda a favor, también, del ahorro de costes para las instituciones.

Hoy menos empresas se ven precisadas a alquilar espacios físicos $y$, en buena cuenta, el uso de plataformas como Zoom, Google Meet o Microsoft Teams desarrolla una fuerte competencia con el mundo presencial. Y aunque aseveremos con certeza que las plataformas tecnológicas no pueden reemplazar la calidez de la presencialidad, un importante contexto a definir es, una vez amaine la pandemia, cuánto de estas plataformas ha de quedar vigente en las reuniones de trabajo a futuro. Naturalmente nos inclinamos por la idea de que muchos de estos aplicativos han de seguir vigentes, en gran medida, en el mundo laboral, en razón de las ventajas que suponen en varios de los aspectos de la relación de trabajo.

Adicionalmente, también como aspecto trascendental, $\mathrm{y}$ a tenor de los ítems antes acotados, hoy el tiempo libre asume otra dimensión y creemos es su calidad de disfrute. La COVID-19 nos ha enseñado a valorar más y de mejor forma la calidad del tiempo sin labores de que ahora disponemos, naturalmente variando esto en función de la naturaleza de la ocupación que tengamos. Así, será muy diferente el tiempo libre para quien forma parte de la planilla de una institución, en relación con el tiempo libre de una contratación free lance, o de quien recurre al autoempleo. Sin embargo, en 
todos los casos mencionados existe una variable en común: aquellos espacios laborales que la pandemia ha permitido identificar como espacios personales, han redefinido una extensión del tiempo libre, lo cual obliga a una nueva comprensión personal de este.

Bajo ese orden conceptual, no podemos dejar de señalar la importancia de los efectos positivos de nuestra perspectiva en cuanto al goce de los derechos humanos más inmediatos y vinculados al libre desarrollo de la personalidad, a pesar de la considerable cantidad de cifras negativas que la COVID-19 deja a su paso en nuestras vidas. $\mathrm{Y}$ he aquí que viene a erigirse otra cuestión de no menor importancia: ¿era necesaria una crisis general de la dimensión que hoy ha generado la pandemia para darnos cuenta de la importancia que reviste un derecho de tanta relevancia como el derecho al libre desarrollo de la personalidad? Aun contra nuestras convicciones de contexto, esbozamos que la respuesta habría de ser positiva.

La pandemia nos deja, de la misma forma, importantes lecciones positivas en materia de derechos humanos desde una perspectiva de la integridad de estos. En tanto, si bien las reflexiones que anteceden obedecen más a una perspectiva de vida en general, debemos aseverar que los derechos humanos asumen una visión no solo de positividad en cuanto al derecho mismo, sino también está de por medio su trascendencia axiológica.

Desde ese contexto, la COVID-19 nos ha instado a revalorar nuestros derechos, a distinguir que a pesar de las restricciones generales de las libertades públicas, los derechos humanos nunca perdieron su carácter inalienable, y si bien las circunstancias obligan hoy, en general, a una restricción de derechos, es también importante la naturaleza de potencialidad, como perspectiva de goce de su ejercicio, que siempre revistieron los primeros derechos de la persona. 
Entonces, podrá relegarse a las familias a quedarse en sus domicilios, o bien limitarse las actividades de los espacios públicos dedicados al goce del derecho al tiempo libre, pero, invariablemente, deberemos entender que se trata más de una restricción que de la suspensión o eliminación de un derecho. Esto último sí es grave, pues el derecho en sí mismo desaparece y ello sería la eliminación de un derecho por sí mismo. La suspensión, a su vez, sigue siendo un escenario peyorativo, pero menor en intensidad, ya que no hay en absoluto ejercicio del derecho de manera temporal. Desde esa conceptualización, entendemos como mejor definición la restricción de derechos, pues el derecho simplemente es atenuado en cuanto a su valor, no desaparece del todo, y se restringe su ejercicio. En ese orden de ideas y para graficar mejor nuestra idea, por supuesto que una persona podrá transitar por la calle, incluso en situación de emergencia, pero a condición de que una causal suficientemente válida, por ejemplo, un grave problema de salud, lo justifique. En ese sentido, es más propio aludir a que los derechos se restringen y no que se eliminan o suspenden. En consecuencia, la pandemia nos ayuda a identificar, de mejor forma, que una restricción de derechos es una forma de contextualizar, de forma más progresiva, la naturaleza de los derechos humanos en tiempos de la COVID-19.

Por último, la crisis de la actual pandemia nos deja, como un legado de relevancia, importantes lecciones, quizá ominosas, como parece enunciar la profesora Woods, en materia de gobernanza. ¿Y qué es lo positivo en medio de esa ciénaga negativa? Consideramos que sobre la acotada materia es importante concluir que los estándares de buena gobernanza, delineados en barómetros como el GHSI, no necesariamente garantizan buenos resultados, y aunque los casos de la realidad son muy dinámicos, pues en todo el mundo las variaciones de acción de los gobiernos conducen a diferentes resultados. Senegal y Sri Lanka, ejemplos anotados en este análisis, 
pueden revestir mejores resultados que los de democracias gigantes como las de EE. UU. y el Reino Unido, en los términos que antes hemos descrito.

Por tanto, hay otras variables a considerar para la buena gobernanza de la crisis de la COVID-19, y es positivo, en definitiva, que la condición de ser un país en vías de desarrollo, con restricciones de diverso orden, pueda incluso conducir, a mérito de decisiones bien llevadas, a buenos resultados, como ha sucedido en los casos descritos.

\section{CONCLUSIONES}

La pandemia generada por la COVID-19 ha modificado radicalmente la convivencia de los seres humanos desde su irrupción en 2020, y en especial, ha transformado el panorama de los derechos de las personas a través de diversas medidas que, aunque necesarias, son de suyo discutibles si nos atenemos a ese matiz de progresividad que los derechos humanos han mostrado como rasgo distintivo en los últimos decenios.

De esa relación entre pandemia y derechos se generan varios supuestos complejos: aquella implica la restricción de derechos en tanto que estos pretenden conservar su carácter inalienable. Ello da lugar a una pugna constante entre los gobiernos, promoviendo medidas limitativas de las libertades públicas, y los ciudadanos que, en medio de ese símil de guerra civil a la que hace mención Agamben respecto de los estados de excepción, buscan que no se restrinjan severamente tantas libertades públicas.

En ese tránsito, hemos postulado una noción de inalienabilidad de los derechos humanos, y así nos lo recuerdan los organismos regionales de protección de los derechos humanos. Al respecto, entonces, los Estados podrán adoptar medidas restrictivas para el 
combate contra la COVID-19, mas ello deberá realizarse dentro de una necesaria línea de tutela de los derechos humanos, siendo el marco material precisamente los criterios de protección mínima de los derechos humanos promovidos por estas entidades de tutela en sus diversos pronunciamientos.

Ha sido un campo importante de trabajo en este estudio el abordaje de la idea de gobernanza como concepto material, en la medida que es precisamente a través de las líneas directrices de acción de los gobiernos en sus esfuerzos contra la COVID-19 que valoramos la dimensión de los resultados de las medidas dispuestas. A ese respecto, hemos reseñado cómo medidas oportunas, pragmáticas e inmediatas de dos países, como Senegal y Sri Lanka, han logrado resultados inmediatos, aunque siempre provisionales, en su lucha contra la pandemia, por sobre las medidas de acción de naciones como EE. UU. y el Reino Unido, países que a pesar de encontrarse en lugares expectantes en el GHSI, un índice de valoración de acción preventiva de los Estados frente a las pandemias, han mostrado resultados de suyo insuficientes. Por tanto, corresponde una reformulación de la noción de gobernanza, y es nuestra idea que se requiere una dosis de pragmatismo en la lucha sin cuartel contra la COVID-19.

De otro lado, en el necesario redimensionamiento de los derechos humanos a partir de la pandemia, consideramos reafirmar y reiterar su inalienabilidad, ya señalada, pero desde una dimensión de continua progresividad y no regresividad de estos derechos. En efecto, la pandemia parece denotar que los derechos retroceden, que estos ceden ante tantas medidas restrictivas de los Estados, que parecen perder su contenido material y, sin embargo, los derechos humanos nunca perdieron, en todos estos tempi bui, o tiempos aciagos de pandemia, su esencia constitutiva, su núcleo duro, su contenido esencial, pues ellos constituyen parámetro de acción y 
norte de referencia para los Estados. De manera tal que no obstante la fuerza de irrupción de la pandemia, es menester atender a que los derechos humanos no pueden perder su trascendencia material.

Adicionalmente, rescatamos algunas lecciones positivas frente a tantos escenarios negativos que nos deja la pandemia. Postulamos que la COVID-19, a pesar de su peligrosidad, nos ha dejado importantes enseñanzas, entre ellas, la revaloración del tiempo libre, del tiempo en familia, del tiempo laboral, entre otras facetas de la vida contemporánea. Es cierto que tantas restricciones debían, de alguna forma, contener también un efecto de orden positivo en nuestras vidas, y ello se traduce, desde nuestro punto de vista, en la cuestión medible de que, en efecto, la pandemia nos ha inducido a cambios sustantivos en nuestras vidas, y hemos querido sacar, de ese contexto, alcances de valor.

En ese sentido, las nociones de pandemia, gobernanza y derechos humanos constituyen un trípode que nos debe servir de marco de reflexión para mejorar la calidad de los derechos de las personas, pues finalmente a ello apuntan los esfuerzos por una mejor gobernanza, y aun cuando la pandemia pugne por restringir nuestras libertades fundamentales, cual Sísifo, los derechos vuelven a rodar, una y otra vez, por las pendientes de la realidad, sin perder su esencia existencial.

\section{REFERENCIAS}

Bachelet, M. (2020). Gobernanza y protección de derechos civiles y políticos en contexto de pandemia COVID-19. En Programa de Salud Global, Escuela de Salud Pública y Unidad de Redes Transdisciplinarias, Vicerrectoría de Investigación y Desarrollo, Universidad de Chile, Gobernanza y protección de derechos civiles y políticos en contexto de pandemia 
COVID-19. Position Paper n. ${ }^{\circ}$ (pp. 15-30). Universidad de Chile. https://www.uchile.cl/publicaciones/171248/position-papergobernanza-y-proteccion-de-derechos-en-pandemia

Comisión Interamericana de Derechos Humanos (2020). Resolución n. ${ }^{\circ}$ 1/2020. Pandemia y derechos humanos en las Américas. (Adoptado por la CIDH el 10 de abril de 2020). https://www. oas.org/es/cidh/decisiones/pdf/Resolucion-1-20-es.pdf

Corte Interamericana de Derechos Humanos (2020a). Declaración de la Corte Interamericana de Derechos Humanos 1/20. 9 de abril de 2020. COVID-19 y derechos humanos: los problemas y desafíos deben ser abordados con perspectiva de derechos humanos y respetando las obligaciones internacionales. https:// www.corteidh.or.cr/tablas/alerta/comunicado/declaracion _1_20_ESP.pdf

Corte Interamericana de Derechos Humanos (2020b). Informe anual 2019. https://www.corteidh.or.cr/docs/informe2019/espanol.pdf

European Court of Human Rights (2020). Annual Report 2019. https://www.echr.coe.int/Documents/Annual_report_2019_ ENG.pdf

González Placencia, L. (2013). Democracia, gobernabilidad y derechos humanos. El Cotidiano, (180), 5-9. https://www.redal yc.org/pdf/325/32528338009.pdf

Naciones Unidas (2008). Prácticas de buen gobierno para la protección de los derechos humanos. https://www.ohchr.org/Documents/ Publications/GoodGovernance_sp.pdf

Nash Rojas, C. (2020). La pandemia del COVID-19 y los derechos humanos en Chile. En Programa de Salud Global, Escuela de Salud Pública y Unidad de Redes Transdisciplinarias, Vicerrectoría de Investigación y Desarrollo, Universidad de Chile, Gobernanza y protección de derechos civiles y politicos en contexto 
de pandemia COVID-19. Position Paper n. 2 (pp. 45-58). Universidad de Chile. https://www.uchile.cl/publicaciones/171248/ position-paper-gobernanza-y-proteccion-de-derechos-enpandemia

Noticias ONU (2020, 24 de septiembre). El mundo reprobó el examen de cooperación frente a la pandemia, urge repensar el multilateralismo: Guterres. https://news.un.org/es/story/2020/ 09/1481212

Oxfam (2020). La COVID-19 y los derechos humanos. https://oxfa milibrary.openrepository.com/bitstream/handle/10546/ $621037 /$ dp-covid-19-human-rights-principles-070820 -advance-es.pdf;jsessionid $=9893451$ B7C1C8D0540543FF B2F393947? sequence $=5$

Sanahuja, J. A. (2020). COVID-19: riesgo, pandemia y crisis de gobernanza global. En Mesa, M. (coord.), Riesgos globales y multilateralismo: el impacto de la COVID-19. Anuario CEIPAZ 2019-2020 (pp. 27-54). https://ceipaz.org/wp-content/uploads/ 2020/05/0.2020-ANUARIO-COMPLETO.pdf

Woods, N. (2021, 3 de enero). Las brutales lecciones de gobernanza del 2020. El Comercio, 22.

Zavala de Alba, L. E. (2015). Gobernanza en derechos humanos: hacia una eficacia y eficiencia institucional. Comisión Nacional de los Derechos Humanos. http://appweb.cndh.org.mx/biblioteca/ archivos/pdfs/fas_CPCDH18.pdf 